\title{
Metodologia de análise dos riscos em áreas de ocorrência de carste urbano: estudo aplicado ao município de João Pessoa, Estado da Paraíba - Brasil
}

\author{
Methodology of risk analysis in areas of occurrence of urban \\ karst: study applied to the municipality of João Pessoa, State of \\ Paraíba, Brazil
}

\begin{abstract}
Caio Lima dos Santos, Centro de Humanidades/Departamento de Geografia, Universidade Estadual da Paraíba, Brasil, caiolimageo@gmail.com

(1) https://orcid.org/0000-0002-6522-2603

Osvaldo Girão da Silva, Centro de Filosofia e Ciências Humanas/Departamento de Ciências Geográficas, Universidade Federal de Pernambuco, Brasil, osgirao@gmail.com
\end{abstract}

(1) https://orcid.org/0000-0002-5797-4450

Saulo Roberto de Oliveira Vital, Departamento de Geografia, Universidade Federal do Rio Grande do Norte, Brasil, srovital@gmail.com

(1) https://orcid.org/0000-0002-2028-0033

Resumo: O presente manuscrito tem por objetivo propor um método de análise dos riscos relacionados ao relevo cárstico em área urbana, que tem como princípio a abordagem de todos os elementos componentes do sistema cárstico urbano, de forma integrada. Considera-se, portanto, os aspectos relativos à dinâmica física natural, bem como os aspectos relativos à dinâmica urbana. Sendo assim, 0 desenvolvimento deste trabalho consiste na descrição do referido procedimento metodológico. Indicase sua adoção no que tange os estudos dos riscos em ambientes cársticos em área urbana. Destarte, considerar e correlacionar a dinâmica evolutiva do relevo cárstico e as interferências antrópicas na formação de áreas de risco cárstico torna-se essencial.

Palavras-chave: Cárste Urbano; Metodologia; Geomorfologia Cárstica.

Abstract: The purpose of this manuscript is to propose a method for analyzing the risks related to karst relief in an urban area, which has as its principle the approach of all the elements that make up the urban karst system, in an integrated manner. Therefore, aspects related to natural physical dynamics are considered, as well as aspects related to urban dynamics. Therefore, the development of this work consists of the description of the referred methodological procedure. Its adoption is indicated with regard to the study of risks in karst environments in urban areas. Thus, considering and correlating the evolutionary dynamics of karst relief and anthropic interferences in the formation of karst risk areas is essential.

Keywords: Urban karst; Methodology; Karst Geomorphology.

\section{Introdução}

O estudo dos riscos associados aos processos cársticos em áreas urbanas demanda a adoção de métodos investigativos adequados aos aspectos relativos à dinâmica do relevo cárstico, sobretudo no que se refere ao cárste subjacente. 
Essa condição está relacionada a dinâmica desse relevo, representada pelos processos subsuperficiais. Sua investigação exige a adoção de métodos específicos, considerando os fatores condicionantes do ambiente cárstico, além da dinâmica antrópica, uma vez que os riscos observados nessas áreas são originados direta ou indiretamente por ações humanas. Desse modo, impactos causados podem ter consequências imprevisíveis (De Waele et al., 2011; Gutiérrez et al., 2011, Gutiérrez, 2016).

A maior dificuldade para o estudo de áreas cársticas está na ocorrência de processos ativos em subsuperfície, controlados pela água, que na maioria das vezes não são diretamente observáveis, o que confere aos processos cársticos um caráter oculto, não despertando assim tanto a atenção da sociedade (Gutiérrez et al., 2014). O caráter oculto da rede drenagem no ambiente cárstico torna extremamente difícil a previsão de resposta do sistema às alterações induzidas pelo homem. Além disso, o sistema cárstico apresenta alta sensibilidade dos elementos geomorfológicos e hidrológicos que o compõem frente às alterações na paisagem (De Waele et al., 2011).

No entanto, a dinâmica desses ambientes pode ser identificada na superfície e suas evidências superficiais devem ser consideradas para o desenvolvimento urbano (Pueyo Anchuela et al., 2015). De modo geral, tais evidências se relacionam a um conjunto de formas de topografia negativa (depressões), representadas por poljés, uvalas e dolinas (Frumkin, 2013).

Nesse aspecto a ocupação urbana em áreas cársticas representa fator potencializador ou até mesmo deflagrador da gênese e evolução desse relevo, haja vista as alterações superficiais promovidas no processo de urbanização.

Partindo dessa premissa, compreende-se que o estudo dos riscos relativos ao cárste em ambiente urbano precisa considerar a dinâmica superficial, a dinâmica subsuperficial, bem como a interação entre elas.

Essa relação entre carste e área urbana é observada no município de João Pessoa, cuja formação do relevo sofre influência direta de processos subsuperficiais, decorrentes de suas características geológicas. O referido município apresenta elevada taxa de urbanização, acompanhada de severas alterações topográficas impetradas pelas diversas atividades antrópicas desenvolvidas, que por seu turno se manifestam na paisagem na elaboração de situações de risco.

Desse modo, o presente manuscrito tem por objetivo propor um método de análise dos riscos relacionados ao relevo cárstico em área urbana, que tem como princípio a consideração de elementos componentes do sistema cárstico urbano, de forma integrada.

\section{Síntese Geoambiental do Município de João Pessoa}

O município de João Pessoa (Figura 1), capital do estado da Paraíba, está inserido na porção leste do estado, na zona costeira. Esta região é marcada pelo predomínio 
de aspectos físico-naturais de zonas úmidas, representadas por características típicas como o porte arbóreo da vegetação, solos profundos, rios caudalosos e chuvas concentradas entre o período outono/inverno, apresentando os maiores volumes pluviométricos entre os meses de junho, julho e agosto, acompanhados de altas temperaturas e baixa amplitude térmica (Figura 2).



Figura 1: Localização do município de João Pessoa-PB.

Fonte: Os autores.

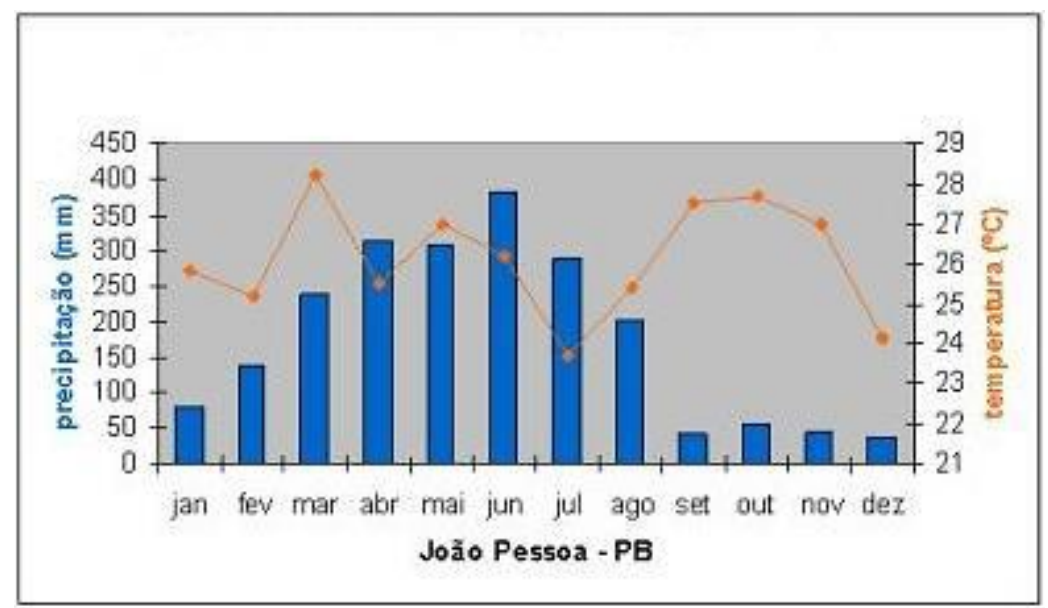

Figura 2: Dados climáticos - precipitação e temperatura média para a cidade de João Pessoa-PB.

Fonte: INMET (Instituto Nacional de Meteorologia) 
As condições geológicas observadas no contexto da área de estudo representam, em associação com as condições climáticas, fatores preponderantes na configuração do relevo e, consequentemente, na sua caracterização geoambiental, sendo observada uma topografia relativamente plana, pouco dissecada.

A formação geológica desse ambiente está associada à evolução tectônica sedimentar da margem continental brasileira (Araújo, 1993). A bacia sedimentar marginal Paraíba, se localiza entre os estados de Pernambuco e Paraíba, especificamente fazendo limite ao norte com a bacia Potiguar e ao sul com o lineamento Pernambuco. A referida bacia está subdividida nas sub-bacias Alhandra (onde se insere o município de João Pessoa), Miriri e Olinda (Mabesoone e Alheiros, 1988; Lima Filho, 1998; Barbosa e Lima Filho, 2005; Barbosa, 2007).

Dentro dos seus limites, a bacia da Paraíba apresenta estratigrafia disposta em camadas de rochas de origem marinha (Calcário da Formação Marina Farinha e Formação Gramame) e terrígenas (arenitos da formação Beberibe/ltamaracá). Recobrindo essas camadas, estão os sedimentos da Formação Barreiras, formada predominantemente por sedimentos argilosos e arenosos (Figura 3). Observa-se que a Formação Maria Farinha não ocorre dentro dos limites territoriais do município de João Pessoa (Barbosa, 2007; Brito Neves et al., 2009).

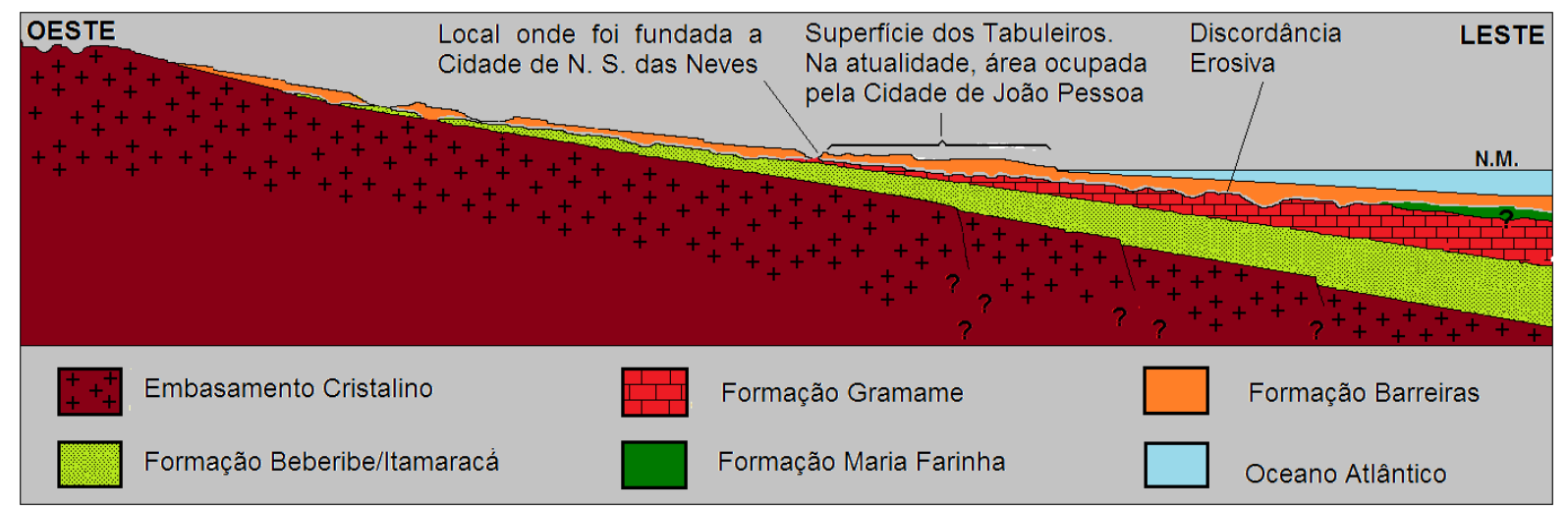

Figura 3: Perfil geológico hipotético Leste-Oeste da Sub-bacia Alhandra.

Fonte: Araújo, 2012.

É sobre os depósitos da Formação Barreiras que ocorrem os baixos planaltos costeiros ou tabuleiros litorâneos, exibindo cotas altimétricas variando entre 49 e 77 metros, destacando-se como a feição predominante no município de João Pessoa (Furrier et al., 2006). Além dessa unidade morfológica, destaca-se a ocorrência de Planícies Fluviais, Planície Fluviomarinha e Planície Costeira, de falésias e de vertentes (Furrier, 2007).

As feições associadas a morfologia cárstica ocorrem com mais evidência sobre os tabuleiros litorâneos, mas também estão associadas às ocorrências superficiais de carbonatos (Vital, 2015), que, conforme a classificação geomorfológica para a área de estudo proposta por Barbosa (2015), se enquadram como morfologias resultantes de 
processos atuais (Quaternário), estando sua origem relacionada ao processo de dissolução atuante nos calcários da formação Gramame.

Conforme o Instituto Brasileiro de Geografia e Estatística - IBGE (2019), atualmente o município de João Pessoa apresenta população estimada em torno de 809.015 mil habitantes e densidade demográfica de $3.421,28 \mathrm{hab} / \mathrm{km}^{2}$. O processo de urbanização é recente, sendo observado com mais evidência a partir da década de 1980.

As áreas periféricas apresentam uma característica peculiar, instalando-se, predominantemente ao redor dos corpos hídricos, fazendo com que as margens de rios e lagoas estejam fortemente urbanizadas e densamente povoadas, com poucas exceções, tanto do ponto de vista da ocupação urbana, quanto ao tipo predominante de ocupação, notadamente as habitações inadequadas.

\section{Identificação e Mapeamento das feições Cársticas}

Os processos cársticos são responsáveis pela elaboração de diversas formas de relevo terrestre, podendo se manifestar tanto em superfície quanto em subsuperfície. As depressões cársticas (dolinas, uvalas e poljés) constituem as formas típicas do ambiente cárstico, resultantes do processo de dissolução de rochas, sobretudo as carbonáticas.

Em áreas urbanas, a identificação dessas feições superficiais constitui tarefa que necessita de apoio de material cartográfico que disponha de boa resolução espacial, capaz de identificar os divisores das depressões, tanto aquelas que apresentam desnível topográfico bem perceptível, quanto aquelas cujo desnível topográfico se apresenta de forma suave. Além desses aspectos, é importante considerar as alterações superficiais promovidas no processo de urbanização, descaracterizando as formas, o que gera, por vezes, a impossibilidade de visualização das depressões.

Nesse contexto a utilização de dados de alta precisão topográfica, como, por exemplo, imagens do sensor de varredura a laser LiDAR (Light Detection And Ranging) ou até fotografias aéreas produzidas VANT (Veículo Aéreo Não-Tripulado) contribui para o processo de delimitação das depressões de modo mais preciso. No entanto, é necessário considerar que as alterações superficiais decorrentes da ocupação humana podem descaracterizar as depressões, promovendo pequenos desníveis topográficos, o que pode induzir o pesquisador a desconsiderar uma determinada área em detrimento dessas alterações. Isto posto, é indispensável a consulta a variados documentos cartográficos, como as cartas topográficas, fotografias aéreas e imagens de satélite de diferentes temporalidades.

Sendo assim, a identificação e delimitação de depressões cársticas em áreas urbanas, num primeiro momento pode se valer dos seguintes critérios: a ocorrência de drenagem radial centrípeta e a distribuição das curvas de nível (Figura 4). Essa análise pode ser realizada a partir de dados obtidos do modelo digital de elevação, seguindo os seguintes procedimentos:

- Extração automática das drenagens; 
- Geração automática de curvas de nível;

- Delimitação manual das bacias fechadas com base na drenagem radial centrípeta e na distribuição das curvas de nível.
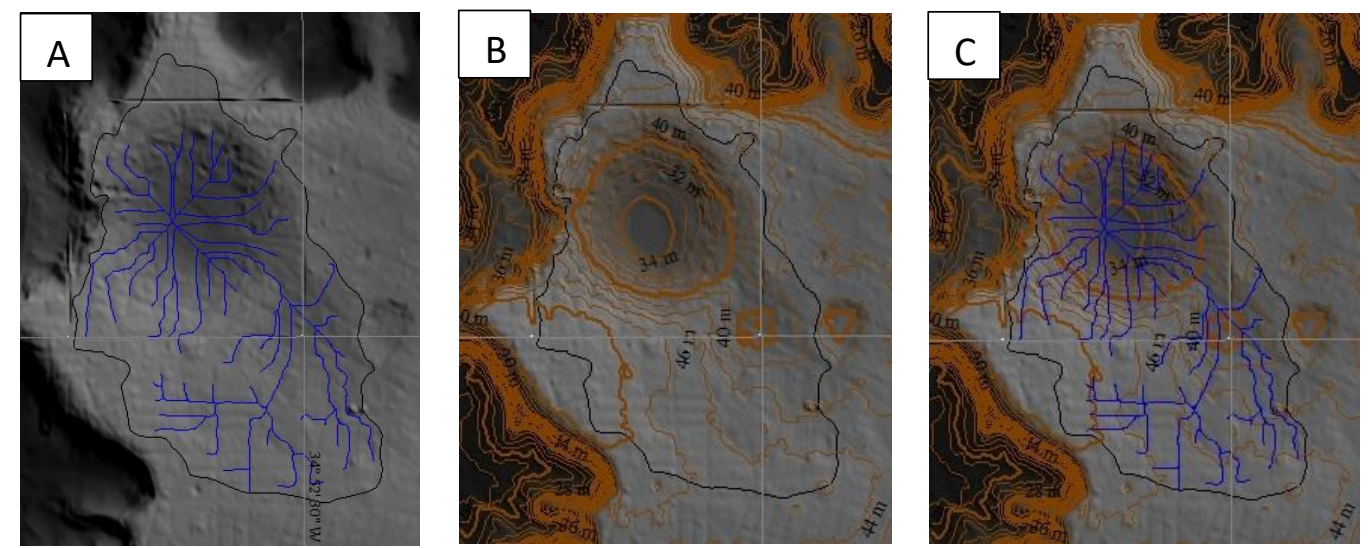

Figura 4: procedimentos adotados para a delimitação de depressões fechadas no município de João Pessoa (PB), Brasil. a) Drenagem radial centrípeta; b) Distribuição das curvas de nível; c) Drenagem e curvas de nível.

Fonte: Os autores.

Outro procedimento necessário consiste na análise de imagens do satélite multitemporais (Figuras 5 e 6), cartas topográficas, fotografias aéreas (Figura 7), etc., tendo como objetivo identificar depressões que possam estar atualmente com suas formas originais alteradas.

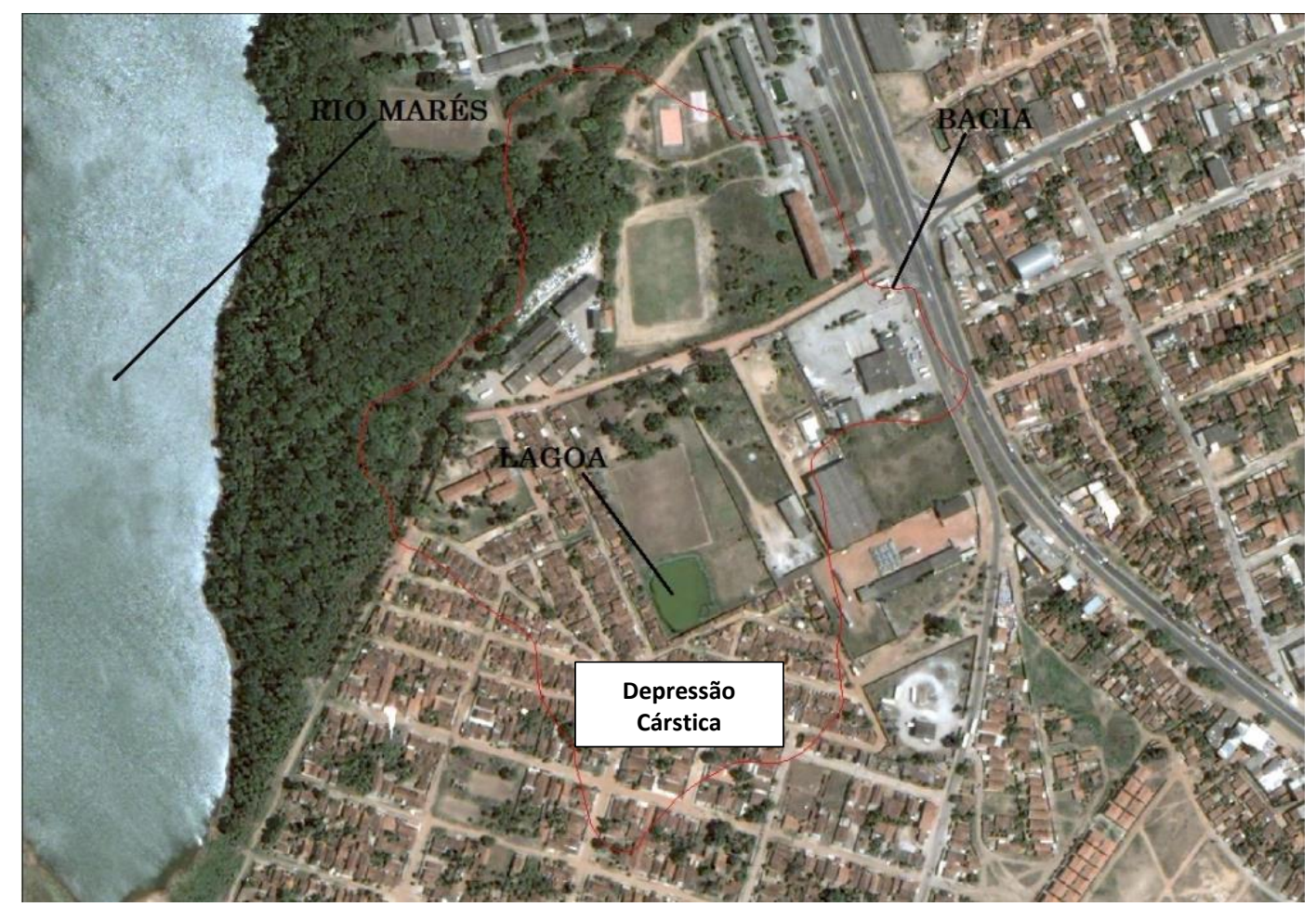

Figura 5: identificação de depressões cársticas em área urbana associada a ocorrência de lagoa, no município de João Pessoa, estado da Paraíba, Brasil, registrada em imagem de satélite capturada no ano de 2008.

Fonte: Secretaria de Planejamento do Município de João Pessoa (SEPLAN). 


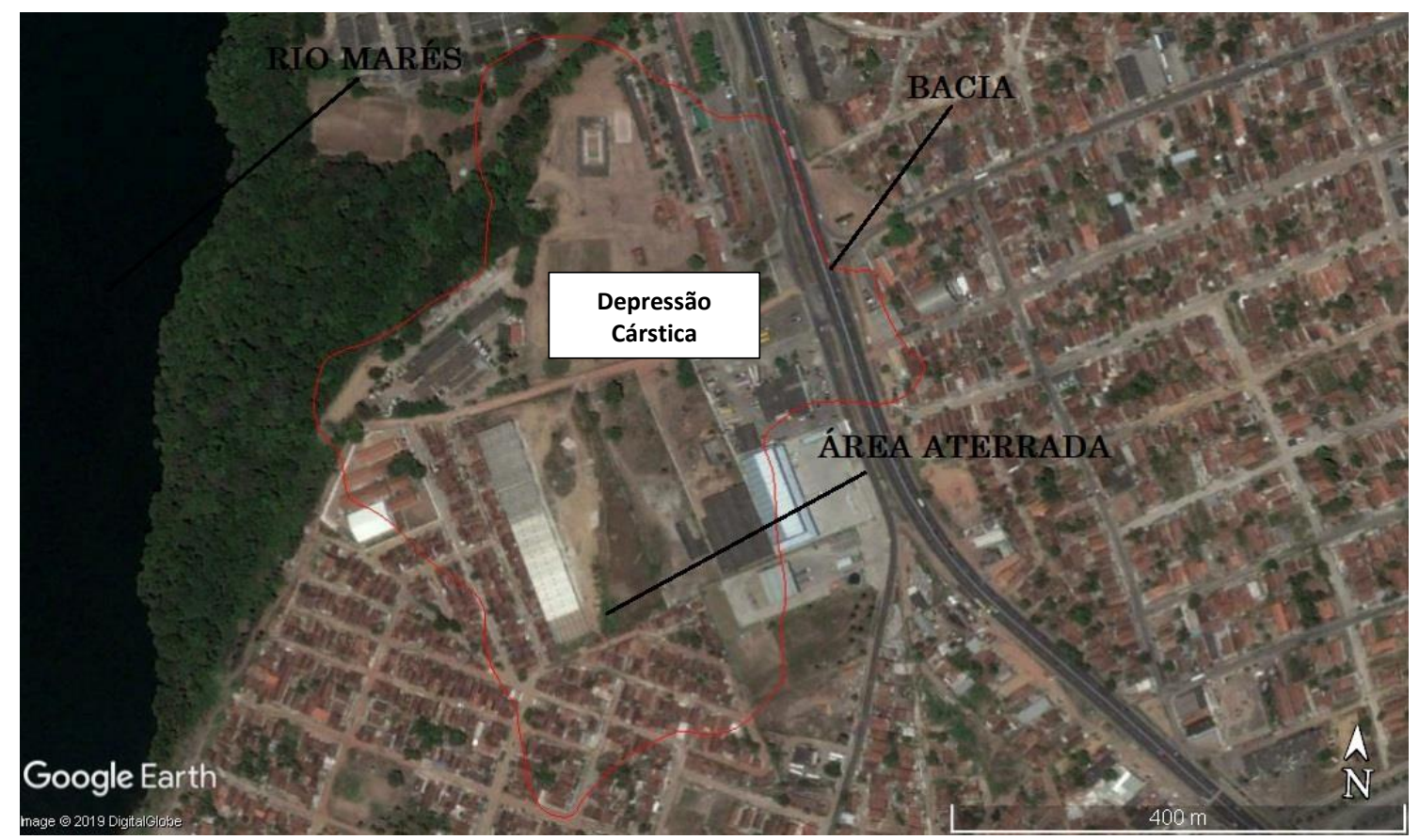

Figura 6: imagem da área representada na figura 02 após o soterramento da lagoa, registrada em imagem de satélite capturada no de 2012.

Fonte: Google Earth.

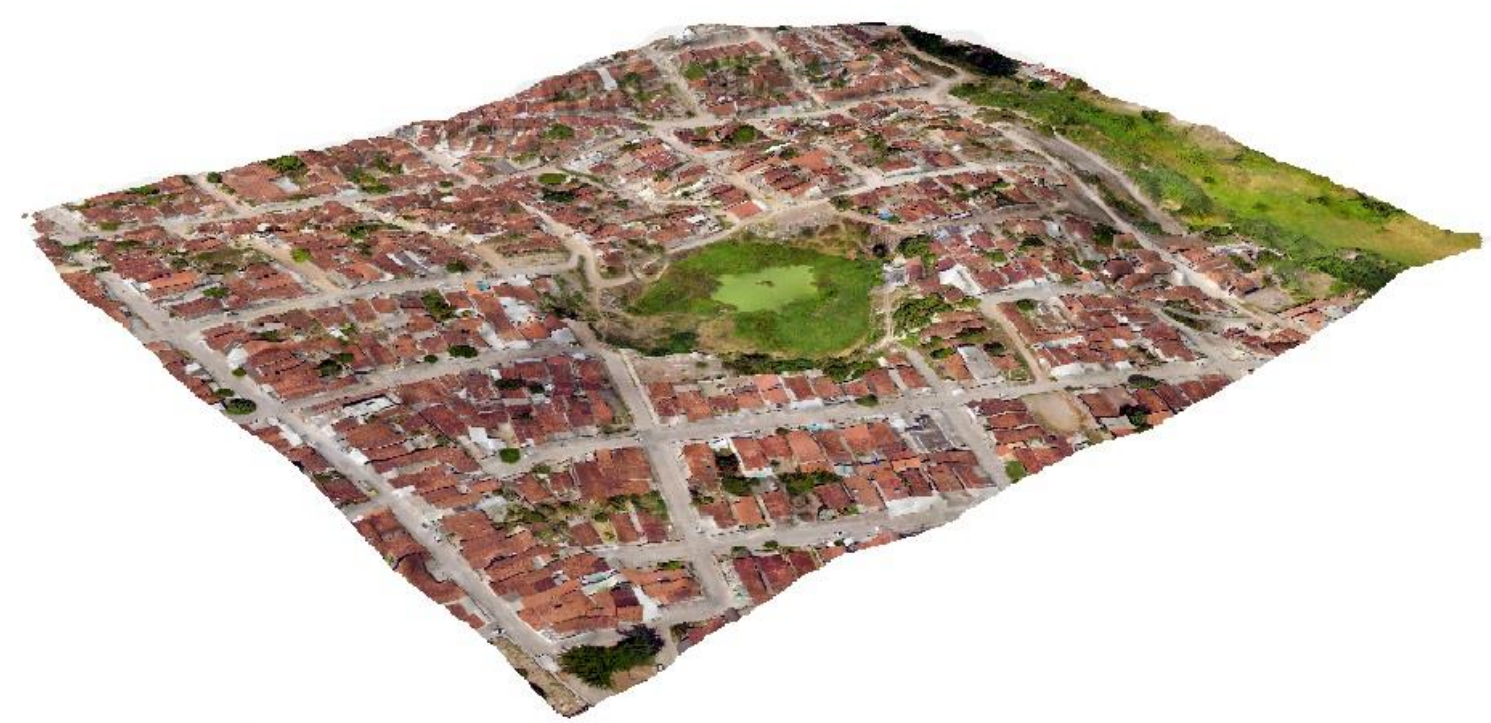

Figura 7: Ortomosaico sobreposto ao modelo digital de elevação (MDE) elaborado a partir de imagens capturadas por VANT (veículo aéreo não-tripulado). No centro da imagem é possível observar a ocorrência de uma depressão cárstica numa área fortemente urbanizada do município de João Pessoa, estado da Paraíba, Brasil.

Fonte: os autores.

Esse procedimento possibilita verificar cartograficamente as características topográficas, morfológicas e as alterações superficiais impetradas no processo de urbanização nas depressões cársticas. Essa etapa é fundamental e indispensável no que se refere à análise dos riscos. 


\section{Caracterização das Depressões Cársticas quanto a sua Gênese e Morfodinâmica}

\subsection{Caracterização morfométrica}

A análise morfométrica de depressões cársticas encontra respaldo na proposta de Williams (1972). A partir da adoção desse critério é possível obter valores de área, perímetro, amplitude altimétrica, altitude máxima, altitude mínima, declividade média, tamanho do eixo maior e do eixo menor, elipsidade, simetria interna e relação profundidade/diâmetro.

A obtenção dos Índices morfométricos contribuem para verificar a dinâmica evolutiva das depressões, bem como indicar fatores naturais deflagradores da sua gênese. Além disso, os valores relativos a esses índices podem ser obtidos em sua maioria de forma automática, com o auxílio de software de geoprocessamento.

A dinâmica evolutiva das depressões pode ser expressa de forma numérica. De modo geral, depressões com baixa amplitude altimétrica (diferença entre o ponto mais elevado e o ponto mais profundo) e baixa declividade média tem origem associada a processo de subsidência lenta do terreno; aquelas que detêm forma poligonal e assimétrica têm sua gênese relacionada a condições estruturais do relevo; o tamanho dos eixos (maior e menor) permitem verificar tamanho e largura da depressão, além de indicar a orientação preferencial de lineamentos estruturais e fraturas nas rochas que atuam na sua gênese. Esses aspectos podem ser submetidos a análise de correlação, possibilitando a comparação de parâmetros obtidos para todas as feições mapeadas, que pode se revelar em padrão de uniformidade evolutiva, sendo fundamental para compreender como evolui o relevo cárstico.

A obtenção dos dados morfométricos ganha fundamental contribuição dos softwares de geoprocessamento, permitindo maior eficácia e agilidade na coleta dos dados, além de atribuir ao pesquisador visão abrangente sobre sua área de estudo.

\subsection{Análise da suscetibilidade natural}

A análise da suscetibilidade natural consiste em verificar a suscetibilidade à ocorrência de fenômenos relativos à evolução natural do relevo cársticos. Para tanto, é necessário considerar elementos da dinâmica do relevo a partir dos seguintes aspectos: litologia (ocorrência de rochas carstificáveis, sobretudo as carbonáticas); condições estruturais (falhas, fraturas e lineamentos estruturais, que nesse caso se relacionam a porosidade secundária das rochas); espessura do material capeador da camada rochosa cástificável subjacente (influência no contato do cárste subjacente e os fluxos superficiais); e geomorfologia (dinâmica do relevo).

O primeiro passo é a elaboração de mapa geológico, descrevendo a ocorrência litológica superficial em escala cartográfica adequada à área de estudo. Em seguida identificar e mapear estruturas e elementos que indiquem o condicionamento estrutural do relevo. O levantamento desse dado pode ocorrer em campo, com o auxílio de bússola geológica, com objetivo de identificar a orientação preferencial de 
fraturas. Falhas e lineamentos estruturais podem ser identificados e vetorizados manualmente com base no MDE.

No caso de ocorrência do carste subjacente, é fundamental observar a espessura da camada capeadora superficial, pois a espessura dessa camada influenciará no maior ou menor contato da rocha carstificável com os fluxos superficiais.

Esse dado pode ser obtido a partir da coleta de dados de subsuperfície, que por seu turno são averiguados através de informações litológicas descritas em documentos referentes a perfuração de poços artesianos, ou através de aplicação de métodos geofísicos, como a eletrorresistividade e GPR (Ground Penetrating Radar). Na maioria dos casos, empresas que atuam na perfuração de poços artesianos realizam a descrição litológica das amostras coletadas no furo, indicando a profundidade em metros de cada camada rochosa, sendo assim possível calcular sua espessura naquele ponto.

Os dados de poços podem ser integrados e interpolados, o que possibilita a criação de um modelo de superfície com auxílio de softwares de geoprocessamento, fornecendo informações acerca da variação topográfica dos extratos rochosos subsuperficiais.

Após a coleta desses dados, o próximo passo é elaborar o mapa de suscetibilidade natural, utilizando o método álgebra de mapas, que nesse caso, serão trabalhados em formato raster. Esse procedimento consiste na atribuição de pesos a cada elemento ou fator analisado, conforme seu nível de importância para a deflagração de processos cársticos.

Desse modo, a atribuição dos pesos aos fatores condicionantes a suscetibilidade aos processos cárstivos se faz de modo subjetivo, sendo fundamental que o pesquisador compreenda como cada elemento atua e se relaciona com os demais componentes do sistema cárstico, para que essa tarefa considere de forma mais precisa possível o grau de influência cada elemento na gênese e evolução do cárste.

\section{Análise da influência antrópica na deflagração dos riscos em áreas cársticas}

Uma proposta eficaz para verificar as ações antrópicas é descrita por Gutiérrez (2016). Esse procedimento metodológico consiste na análise e descrição de campo, tendo como intuito observar a atuação de fatores que podem representar gatilho para a ocorrência de situações de risco. Conforme o referido autor, os processos que envolvem a gênese de uma depressão cárstica podem ser deflagrados ou acelerados devido a mudanças naturais ou antrópicas. Em sua proposta de análise, são considerados os tipos de mudança no sistema cárstico (natural ou antrópico) e os efeitos causados, conforme a Tabela I. Nesse quadro são apresentados alguns fatores antrópicos considerados pelo referido autor, sendo destacados aqueles que foram considerados os de maior relevância para a deflagração dos riscos cárstico em área urbana. 
Tabela I: Mudanças no sistema cárstico e seus efeitos potenciais que podem acelerar ou desencadear o desenvolvimento de dolinas.

\begin{tabular}{|c|c|c|}
\hline Tipos de mudança & Efeito & $\begin{array}{l}\text { (1) Processo natural } \\
\text { (2) Atividades humanas }\end{array}$ \\
\hline $\begin{array}{l}\text { Aumento da entrada } \\
\text { de água no solo }\end{array}$ & $\begin{array}{l}\text { - Aumento da taxa de aceleração da } \\
\text { percolação; } \\
\text { - Favorece a dissolução; } \\
\text { - Pode reduzir a resistência mecânica; }\end{array}$ & $\begin{array}{l}\text { (1) Chuvas } \\
\text { (2) Irrigação }\end{array}$ \\
\hline $\begin{array}{l}\text { Rebaixamento do } \\
\text { lençol freático }\end{array}$ & $\begin{array}{l}\text { - Aumenta o peso efetivo dos } \\
\text { sedimentos (perda de sustentação } \\
\text { flutuante). } \\
\text { - Fluxo freático lento substituído por } \\
\text { descida mais rápida. } \\
\text { - Percolação favorecendo a } \\
\text { sufocamento, especialmente quando } \\
\text { o lençol freático é rebaixado abaixo } \\
\text { da rocha. } \\
\text { - Acelera o fluxo de águas } \\
\text { subterrâneas em áreas afetadas por } \\
\text { cones de depressão. } \\
\text { - Pode reduzir a resistência mecânica } \\
\text { por dessecação e cristalização de } \\
\text { sais. }\end{array}$ & $\begin{array}{l}\text { (1) Mudanças climáticas } \\
\text { (Diminuição do nível } \\
\text { do mar) } \\
\text { (2) Extração de água } \\
\text { subterrânea } \\
\text { (perfuração de poço } \\
\text { artesiano) }\end{array}$ \\
\hline Erosão & $\begin{array}{l}\text { - Reduz a espessura e resistência } \\
\text { mecânica do material sobreposto. } \\
\text { - Pode concentrar o escoamento. } \\
\text { - Pode criar um novo nível de base } \\
\text { alterando o caminho e a taxa dos } \\
\text { fluxos de águas subterrâneas. }\end{array}$ & $\begin{array}{l}\text { (1) Erosão natural } \\
\text { (2) Erosão antrópica }\end{array}$ \\
\hline Perfurações & $\begin{array}{l}\text { - Enfraquece, perfura e sobrecarrega o } \\
\text { teto da cavidade. } \\
\text { - Causa erosão interna favorecida } \\
\text { pelos buracos, vibrações, fluidos de } \\
\text { perfuração e bombeamento. } \\
\text { - Pode induzir fluxos de águas } \\
\text { subterrâneas localizadas e } \\
\text { turbulentas. }\end{array}$ & $\begin{array}{l}\text { (2) Perfuração de poços } \\
\text { artesianos; abertura } \\
\text { de valas para } \\
\text { instalação de dutos. }\end{array}$ \\
\hline $\begin{array}{l}\text { Remoção da } \\
\text { vegetação }\end{array}$ & $\begin{array}{l}\text { - Reduz a resistência mecânica dos } \\
\text { depósitos de cobertura (coesão da } \\
\text { raiz). } \\
\text { - Aumenta a infiltração. }\end{array}$ & $\begin{array}{l}\text { (1) Incêndios naturais } \\
\text { (2) Desmatamento }\end{array}$ \\
\hline
\end{tabular}

Fonte: adaptada de Gutiérrez (2016).

A observação dessas alterações superficiais e suas respectivas respostas à dinâmica dos ambientes cársticos pode ser realizada em atividades de campo, onde o pesquisador deve identificá-las, orientado pelas informações apresentadas na Tabela I. O conhecimento da área de estudo é fundamental, uma vez que aspectos locais podem estar influenciando na dinâmica cárstica, fato que pode não ser observado em outras localidades, e por isso não estar descrito no referido quadro. Portanto, a compreensão da dinâmica local em seus variados aspectos ganha fundamental relevância.

Outra forma de análise pode ser realizada utilizando sensoriamento remoto. Se faz então necessário a elaboração de mapas de cobertura do solo em diferentes 
temporalidades, que pode ser complementada pela análise de documentos históricos e material cartográfico que descrevam a evolução urbana da área estudada. As entrevistas com moradores locais potencializa esse processo, pois estes são, por vezes, as pessoas que estão ocupando esse espaço há muitos anos, além de se configurarem como os próprios autores das transformações realizadas.

\section{Análise dos riscos}

Nessa etapa da pesquisa são desenvolvidos seguintes procedimentos:

- Sobreposição do mapa de suscetibilidade natural ao cadastro urbano da área analisada;

- Verificação e descrição de campo;

- Definição de classes de risco geomorfológico. Essa tarefa deve observar os aspectos de cada área estudada, considerando a suscetibilidade natural e as características da ocupação humana, conforme as observações de campo e a elaboração do mapa de cobertura do solo.

A definição das classes de risco deve ser realizada a partir da compreensão da dinâmica evolutiva natural e as interferências humanas, situação que irá variar de acordo com a dinâmica observada nas diferentes localidades estudadas. Existem localidades que a interferência antrópica está relacionada a extração de água dos aquíferos cársticos; noutra pode se relacionar a introdução de fluídos para a subsuperfície em função da atividade mineradora; noutra pode estar havendo subsidência lenta da superfície em função do soterramento de depressões cársticas. Ou seja, a definição de classes de risco irá variar de acordo com a dinâmica local observada. De modo sintético, a (Figura 8) demonstra o itinerário metodológico que pode ser adotado no desenvolvimento de estudos sobre os riscos cársticos em área urbana.



Figura 8: Organograma representando procedimento metodológico.

Fonte: os autores 


\section{Conclusões}

A análise dos riscos cársticos em áreas urbanas requer a adoção de variados procedimentos de investigação, dependendo da dinâmica observada, se definirá a metodologia adequada, eficiente e acessível para o desenvolvimento da pesquisa. No entanto, procedimentos básicos devem ser realizados, e portanto, figuram como indispensáveis para a obtenção de resultados satisfatórios nesse campo de pesquisa, sendo eles: a análise da dinâmica natural (morfometria, geologia, condições estruturais, estratigrafia e geomorfologia) e a dinâmica antrópica, que nesse caso é caracterizada pelo processo de urbanização.

Compreender os níveis de suscetibilidade à ocorrência de um fenômeno cárstico representa um passo fundamental na prevenção dos riscos, pois estes fenômenos tendem a causar graves prejuízos materiais, além de representar uma real ameaça a vidas humanas. Porém, não é possível estabelecer aqui um nível hierárquico de suscetibilidade de modo generalizado, pois esta é uma condição específica de cada lugar, a depender dos aspectos relativos à gênese e evolução do relevo cárstico. No que se refere aos riscos, a dinâmica social também deve ser compreendida e caracterizada, pois o ambiente cárstico apresenta-se bastante sensível às alterações impostas pelas atividades humanas.

\section{Bibliografia}

Araújo, M. E. (1993). Estudo Geomorfológico do extremo Sul do Litoral da Paraíba. Dissertação Mestrado - Instituto de Geociências, Universidade Federal da Bahia.

Araújo, M. E. (2012). Água e Rocha na Definição do sítio de Nossa senhora das Neves, atual Cidade de João Pessoa - Paraíba. Tese Doutorado - Faculdade de Arquitetura, Universidade Federal da Bahia.

Barbosa, J. A., Lima-Filho, M. (2005). Os domínios da Bacia da Paraíba. In: Anais do Congresso Brasileiro de Pesquisa e Desenvolvimento em Petróleo e Gás. Salvador.

Barbosa, J. A. (2007). A deposição carbonática na faixa costeira Recife-Natal: aspectos estratigráficos, geoquímicos e paleontológicos. Tese Doutorado. Programa de PósGraduação em Geociências. Universidade Federal de Pernambuco.

Barbosa, T. S. (2015). Geomorfologia urbana e mapeamento geomorfológico do município de João Pessoa - PB, Brasil. Dissertação Mestrado em Geografia - Universidade Federal da Paraíba, João Pessoa.

Brito Neves, B. B., Albuquerque, J. P. T., Coutinho, J. M. V., Bezerra, F. H. R. (2009). Novos dados geológicos e geofísicos para a caracterização geométrica e estratigráfica da Subbacia de Alhandra (Sudeste da Paraíba). Revista do Instituto de Geociências. Geol. USP, Sér. Cient., São Paulo, v.9(2), 63-87. http://dx.doi.org/10.5327/z1519-874x2009000200004

De Waele, J., Gutiérrez, F., Parise, M., Plan, L. (2011). Geomorphology and natural hazards in karst areas: a review. Geomorphology, 134(1-2), 1-8. https://doi.org/10.1016/i.geomorph.2011.08.001 
Furrier, M., Araújo, M. E., Meneses, L. F. (2006). Geomorfologia e Tectônica da Formação Barreiras no Estado da Paraíba. Revista do Instituto de Geociências - USP, 6(2), 61-70. http://dx.doi.org/10.5327/S1519-874X2006000300008

Furrier, M. (2007). Caracterização geomorfológica e do meio físico da folha João Pessoa 1:100.000. Tese Doutorado. Programa de Pós-Graduação em Geografia Física. Universidade de São Paulo.

Frumkin, A. (2013). New Developments of Karst Geomorphology Concepts. In: John F. Shroder (ed), Frumkin, A. (Volume Editor). Treatise on Geomorphology, Vol 6, Karst Geomorphology, San Diego: Academic Press. 1-13.

Gutiérrez, F., Galve, J. P., Lucha, P., Castañeda, C., Bonachea, J., Guerrero, J. (2011). Integrating geomorphological mapping, trenching, InSAR and GPR for the identification and characterization of sinkholes in the mantled evaporite karst of the Ebro Valley (NE Spain). Geomorphology, 134(1-2), 144-156. https://doi.org/10.1016/j.geomorph.2011.01.018

Gutiérrez, T., Parise, M., De Waele, J., Jourde, H. (2014). A review on natural and humaninduced geohazards and impacts in karst. Earth-Science Reviews, 138, 61-88. https://doi.org/10.1016/i.earscirev.2014.08.002

Gutiérrez, F. (2016). Sinkhole Hazards. Oxford Research Encyclopedia of Natural Hazard Science. Consultado em 5 de julho de 2019 em: https://oxfordre.com/naturalhazardscience/view/10.1093/acrefore/9780199389407.001.00 01/acrefore-9780199389407-e-40.

Lima Filho, M. F. (1998). Análise estratigráfica e estrutural da bacia Pernambuco. Tese Doutorado - Instituto de Geociências, Universidade de São Paulo, São Paulo.

Mabesoone, J. M., Alheiros, M. M. (1988). Origem da bacia sedimentar costeira PernambucoParaíba. Revista Brasileira de Geociências, 18(4), 476-482.

Pueyo Anchuela, Ó., Casas Sainz, A. M., Pocoví Juan, A., Gil Garbí, H. (2015). Assessing karst hazards in urbanized areas. Case study and methodological considerations in the mantle karst from Zaragoza city (NE Spain). Engineering Geology, 184, 29-42. https://doi.org/10.1016/j.enggeo.2014.10.025

SEPLAN - Secretaria de Planejamento do Município de João Pessoa (PB), Brasil, 2008.

Williams, P. W. (1972). Morphometric analysis of polygonal karst in New Guinea. Geological Society of America Bulletin, 83(3), 761-96. https://doi.org/10.1130/00167606(1972)83[761:MAOPKI]2.0.CO;2

Vital, S. R. O. (2015). Análise geológica-geomorfológica das depressões fechadas e dolinas em sedimentos da Formação Barreiras na região de João Pessoa (PB). Tese Doutorado Programa de Pós-graduação em Geociências, Centro de Tecnologia e Geociências, Universidade Federal de Pernambuco, Recife, PE.

Artigo recebido em / Received on: 16/09/2020

Artigo aceite para publicação em / Accepted for publication on: 05/06/2021 
Santos, Silva e Vital / Physis Terrae, Vol. 3, no 1-2, 2021, 23-35

Página intencionalmente deixada em branco 